\title{
Having Your Cake and Eating It Too: Combining SBRT and Multi-agent Chemotherapy in Locally Advanced Pancreatic Cancer
}

\author{
Amar Kishan ${ }^{1}$, Percy Lee ${ }^{1}$ \\ 1. Department of Radiation Oncology, University of California, Los Angeles \\ $\square$ Corresponding author: Amar Kishan, aukishan@gmail.com \\ Disclosures can be found in Additional Information at the end of the article
}

\section{Abstract}

We read with great interest the results of the LAP07 study comparing capecitabine-based chemoradiation with gemcitabine-based therapy for non-progressive locally advanced pancreatic cancer (LAPC), following four months of gemcitabine-based therapy. The results, consistent with previous data, showed that standard chemoradiation improves local control (LC) but not overall survival. In this brief editorial, we emphasize that LC may still be very important in LAPC, as up to 30\% of patients with LAPC may die from locally progressive disease. This is particularly likely to be true as systemic therapies continue to improve in efficacy. We very briefly review the data in support of stereotactic body radiotherapy (SBRT) for LAPC, which has been shown to offer excellent LC with minimal late grade $\geqslant 2$ toxicity rate in a recent multi-institutional phase II study. We underscore that a short course of SBRT offers an expeditious alternative to a long course of chemoradiation, allowing the use of fully-intensive systemic therapy.

Categories: Radiation Oncology

Keywords: sbrt, pancreatic cancer, lap-07

\section{Editorial}

We read with great interest the results of the LAP07 study comparing capecitabine-based chemoradiation with gemcitabine-based therapy for non-progressive locally advanced pancreatic cancer (LAPC), following four months of gemcitabine-based therapy [1]. The results, consistent with previous data, showed that standard chemoradiation improves local control (LC), but not overall survival.

Received 06/07/2016

Review began 06/08/2016 Review ended 07/02/2016 Published 07/13/2016

\section{C) Copyright 2016}

Kishan et al. This is an open access article distributed under the terms of the Creative Commons Attribution License CC-BY 3.0., which permits unrestricted use, distribution, and reproduction in any medium, provided the original author and source are credited.
One must be cautious, however, to 'not throw the baby out with the bathwater'-we submit that LC is still important in LAPC. Up to 30\% of patients with LAPC die from locally progressive disease [2]. For patients with localized disease and those whose metastatic burden is controlled by effective systemic therapy, LC may be particularly important. The authors astutely discussed that advanced radiotherapy techniques may afford better LC. This is particularly relevant, as LAPC can be heterogeneous not only with regards to a proclivity for metastatic vs. local spread but also with regards to radiosensitivity. Intriguingly, stereotactic body radiotherapy (SBRT), which allows delivery of ablative radiotherapy in $\leqslant 5$ sessions, has demonstrated excellent LC for LAPC [3-4]. The Stanford experience utilizing a single fraction of 25 Gy (with or without conventionally fractionated radiation, primarily in patients treated receiving gemcitabinebased chemotherapy) found an overall LC rate of $84 \%$ at 12 months [3]. Enthusiasm for this 
approach was tempered by the $25 \% 12$-month actuarial rate of late grade $\geqslant 2$ gastrointestinal toxicity. Subsequent multi-fraction SBRT schedules have yielded improved toxicity profiles. For example, a recent phase II multi-institutional study evaluating a dose of 33 Gy in five fractions after up to three weeks of gemcitabine-based therapy reported a 12-month LC rate of 78\%, with an attendant late grade $\geqslant 2$ toxicity rate of only $11 \%$ [4]. Continued technical advancements in radiotherapy delivery may further reduce toxicity by sparing normal tissues, such as the adjacent duodenum.

Because SBRT is delivered in $\leqslant 5$ fractions, it allows patients to quickly resume systemic therapy, eliminating the delay caused by conventionally fractionated chemoradiation [5]. Patients with non-progressive disease on optimal systemic therapy regimens may receive SBRT and then resume systemic therapy in short order. This strategy is being tested in a multiinstitutional prospective phase III study (https://clinicaltrials.gov/ct2/show/NCT01926197) in which patients with non-progressive disease following up to four cycles of FOLFIRINOX are randomized to receive SBRT (40 Gy in 5 fractions) or further FOLFIRINOX. We encourage the oncology community to support this effort to determine if SBRT, incorporated with multi-agent systemic therapy, may improve overall survival. Hopefully, continued investigation will determine the optimal sequencing and combination of systemic and local therapy for patients with LAPC.

We have no conflicts of interest to disclose.

\section{Additional Information}

\section{Disclosures}

Conflicts of interest: In compliance with the ICMJE uniform disclosure form, all authors declare the following: Payment/services info: All authors have declared that no financial support was received from any organization for the submitted work. Financial relationships: All authors have declared that they have no financial relationships at present or within the previous three years with any organizations that might have an interest in the submitted work. Other relationships: All authors have declared that there are no other relationships or activities that could appear to have influenced the submitted work.

\section{References}

1. Hammel P, Huguet F, van Laethem JL, Goldstein D, Glimelius B, Artru P, Borbath I, Bouché O, Shannon J, André T, Mineur L, Chibaudel B, Bonnetain F, Louvet C; LAP07 Trial Group: Effect of chemoradiotherapy vs chemotherapy on survival in patients with locally advanced pancreatic cancer controlled after 4 months of gemcitabine with or without erlotinib: The LAP07 Randomized Clinical Trial. JAMA. 2016, 315:1844-53. 10.1001/jama.2016.4324

2. Iacobuzio-Donahue CA, Fu B, Yachida S, Luo M, Abe H, Henderson CM, Vilardell F, Wang Z, Keller JW, Banerjee P, Herman JM, Cameron JL, Yeo CJ, Halushka MK, Eshleman JR, Raben M, Klein AP, Hruban RH, Hidalgo M, Laheru D: DPC4 gene status of the primary carcinoma correlates with patterns of failure in patients with pancreatic cancer. J Clin Oncol. 2009, 27:1806-13. 10.1200/JCO.2008.17.7188

3. Chang DT, Schellenberg D, Shen J, Kim J, Goodman KA, Fisher GA, Ford JM, Desser T, Quon A, Koong AC: Stereotactic radiotherapy for unresectable adenocarcinoma of the pancreas . Cancer. 2009, 115:665-72. 10.1002/cncr.24059

4. Herman JM, Chang DT, Goodman KA, Dholakia AS, Raman SP, Hacker-Prietz A, IacobuzioDonahue CA, Griffith ME, Pawlik TM, Pai JS, O'Reilly E, Fisher GA, Wild AT, Rosati LM, Zheng L, Wolfgang CL, Laheru DA, Columbo LA, Sugar EA, Koong AC: Phase 2 multi-institutional trial evaluating gemcitabine and stereotactic body radiotherapy for patients with locally advanced unresectable pancreatic adenocarcinoma. Cancer. 2015, 121:1128-37. 10.1002/cncr.29161

5. Schrag D: Optimizing treatment for locally advanced pancreas cancer: progress but no 


\section{Cureus}

precision. JAMA. 2016, 315:1837-38. 10.1001/jama.2016.4284 